\title{
Representação Social e Estereótipo: A Zona Muda das Representações Sociais ${ }^{1}$
}

\author{
Maria Suzana de Stefano Menin ${ }^{2}$ \\ Universidade Estadual de São Paulo - Campus de Presidente Prudente
}

\begin{abstract}
RESUMO - Neste artigo, a partir da definição do conceito de zona muda das representações sociais, descrevemos as técnicas de substituição e de descontextualização normativa desenvolvidas pela Escola de Aix-en-Provence para revelar as representações escondidas ou mascaradas em função de sua inadequação às normas sociais vigentes no grupo de referência dos respondentes de questionários. A seguir, relatamos os primeiros estudos realizados com a intenção de revelar elementos representacionais da zona muda de representações e os estudos atuais sobre esse conceito e descrevemos e discutimos três possíveis explicações para a mudança de representações em situações de substituição ou de descontextualização normativa: a projeção de representações condenáveis pelas normas sociais a outros grupos de representação quando os sujeitos falam por outros grupos e não por si mesmo; o efeito da transparência de representações quando são descritas as representações de grupos conhecidos; o efeito da influência social de normas ou de representações proeminentes no grupo de pertença.
\end{abstract}

Palavras-chave: representações sociais; zona muda das representações; estereótipos; preconceito.

\section{Social Representation and Stereotypes: The Mute Zone of the Social Representations}

\begin{abstract}
In this paper, departing from the definition of the concept of Mute Zone of the social representations, we describe the techniques of substitution and normative descontextualization developed by the school of Aix-en-Provence to disclose the hidden or masked representations due to its inadequacy to the social norms in force in the reference group of the people that answered the questionnaires. Next, we report the first studies carried out with the intention to reveal representative elements of the Mute Zone of representations and the current studies about this concept and we describe and discuss three possible explanations for the change of representations in situations of substitution or normative descontextualization: the projection of the representations that are condemnable by the social norms to other groups of representation when the subject persons speak on behalf of other groups and not by themselves; the effect of the transparency of representations when the representations of known groups are described; the effect of the social influence of norms or proeminent representations in the group where they belong.
\end{abstract}

Key words: social representations; mute zone of the representations; stereotypes; prejudice.

Neste artigo descrevemos alguns estudos que buscam revelar a zona muda ${ }^{3}$ das representações sociais (Abric, 2003), isto é, espaços de representações que embora sejam comuns a um determinado grupo e nele partilhadas, não se revelam facilmente nos discursos diários e, ainda mais, nos questionários de investigação, pois são consideradas como não adequadas em relação às normas sociais vigentes. Os estereótipos negativos e os preconceitos incluem-se nesta categoria e exporemos algumas pesquisas que têm sido recentemente realizadas neste campo pela "Escola de Aixen-Provence"4.

1 Agradecemos a CAPES pela bolsa de pós-doutorado na França no período de setembro de 2004 a setembro de 2005.

2 Endereço: Rua Roberto Simonsen, 305, Centro Educacional UNESP, Presidente Prudente, SP, Brasil 19060-900.E-mail: menin@ @rudente. unesp.br

3 Zone Muette, no original.

4 Entende-se normalmente pela "Escola de Aix" um grupo de pesquisadores, pertencentes à Universidade de Aix-en-Provence, na região de Provence, França, que se dedica à análise estrutural das representações sociais, como Claude Flament, Jean Claude Abric e Christian Guimelli.
Jodelet (1996) e Abric (1996) apontam a importância e a adequação de se estudar fenômenos relacionados à exclusão social através da análise de representações sociais. Para esses autores, embora seja necessário investigar e interferir nos fatores objetivos que intervém na exclusão, isso não é suficiente para a compreensão de um fenômeno que é, também, de natureza simbólica.

No presente trabalho, nos interessamos pelas representações que um grupo de indivíduos pode fazer de outro grupo, alvo de preconceitos. Como captar essas representações? $\mathrm{E}$ em que medida, se pode dizer que são representações sociais?

A Escola de Aix-en-Provence, realizando análise estrutural dos componentes das representações e buscando identificar os elementos centrais das mesmas deparou-se, em algumas investigações, com representações disfarçadas (masquées), ou seja, certos elementos de uma representação apareciam numa situação e não em outras, surgindo então a hipótese da zona muda.

A quase totalidade dos estudos em representação social se baseia nas verbalizações de sujeitos investigadas através de entrevistas, questionários e outros instrumentos identifica- 
dores de discursos. Abric (2003) levanta o problema da confiabilidade dos dados obtidos: "as pessoas que interrogamos nos dizem mesmo o que pensam?" (p. 61). O autor ilustra esse problema se reportando às estatísticas realizadas na França a respeito das eleições presidenciais de 2002. Embora as estatísticas mostrassem Le Pen em terceiro lugar nas intenções de voto (depois de Chirac e Jospin) os resultados reais o colocaram em segundo. Ora, para o autor, provavelmente as pessoas entrevistadas antes das eleições não revelaram suas intenções de voto por temor de serem mal vistas. Assim, conclui Abric, "para certos objetos, em certos contextos, existe uma zona muda de representação social. Esta zona muda é composta de elementos da representação que não são verbalizáveis pelos sujeitos pelos métodos clássicos de coleta de dados" (2003, p. 61).

A zona muda, segundo Guimelli e Deschamp (2000), é composta de elementos da representação que são "contranormativos", ou seja, cognições ou crenças que não são expressas pelo sujeito em condições normais de produção, pois podem entrar em conflito com valores morais ou normas de um determinado grupo. Para Abric (2003), esta zona pode ser composta por certos elementos do núcleo central de uma representação que estão "adormecidos" não por que não estejam ativados, mas porque são "não-expressáveis" (p. 62). Assim, certos elementos da representação, mesmo aqueles que podem ser centrais, podem ficar "escondidos" ou "mascarados" de forma que o que aparece são os elementos periféricos. Considerando, ainda, que os elementos do núcleo central podem ser funcionais ou normativos ${ }^{5}$, Abric (2003) sugere que os que ficam na zona muda são os normativos, pois são estes, mais ligados a avaliações e valores, que aparecem como ilegítimos para o grupo de pertença do indivíduo que representa.

A fim de se conseguir revelar os elementos da zona muda de representação é preciso desenvolver métodos específicos de investigação. E, dado que esta zona é constituída de elementos contra-normativos, para revelá-los é preciso reduzir a pressão normativa sobre o sujeito que representa. Abric (2003) afirma que numa primeira análise, a pressão normativa encontra sua origem em dois elementos da situação: o próprio sujeito e o grupo de referência, e é sobre estes dois aspectos que as técnicas para identificar a zona muda atuarão. A primeira - técnica de substituição - visa reduzir a pressão normativa, reduzindo o nível de implicação pessoal do sujeito com relação à representação do objeto. A segunda - técnica de descontextualização normativa - visa reduzir a pressão normativa colocando o sujeito num contexto mais distante de seu próprio grupo de referência, permitindo-lhe, assim, exprimir mais livremente seu pensamento através da redução dos riscos de julgamento negativo da parte de seus interlocutores.

\section{A técnica de substituição}

Baseia-se na idéia de que um sujeito poderá exprimir representações "proibidas ao seu grupo" atribuindo-as a

5 Segundo Abric (1976) os elementos normativos de uma representação são aqueles que se referem a avaliação, julgamentos, atitudes ou estereótipos em relação ao objeto de representação e os elementos funcionais são os que se referem às práticas exercidas sobre esse objeto. outros, isto é, falando por outros, que não si mesmo. Primeiro, pede-se à pessoa que dê sua própria opinião (associações) sobre um tema; e, a seguir, pede-se que responda como um outro o faria quando interrogado pelo mesmo tema. $\mathrm{O}$ outro deve ser relacionado ao grupo de referência do sujeito; no entanto, o nível de implicação deste outro com a pessoa respondente pode ser manipulado pelo tipo de solicitação feita (pode-se pedir a um estudante de Letras que responda como um estudante de Letras responderia, ou como os "franceses em geral" responderiam).

Abric (2003) faz a ressalva de que a técnica da substituição permite apenas a hipótese de que as representações colocadas são da zona muda. Pode acontecer que as representações fornecidas na substituição sejam representações que os sujeitos têm do grupo de referência (os franceses em geral...) e não aquelas da zona muda. Este é um limite importante da técnica.

\section{A técnica de descontextualização normativa}

A técnica de descontextualização normativa consiste em manipular o receptor das respostas do sujeito, ou seja, a quem o sujeito responde ao questionário; e que pode ser ou alguém do grupo de referência do próprio sujeito, com seus mesmos valores, ou alguém com outros valores. Postula-se que será mais fácil ao sujeito responder, expressando suas idéias desviantes, contra-normativas, em face de uma pessoa menos próxima e que não partilha do mesmo sistema de referência do sujeito.

Abric (2003) exemplifica esta técnica com um estudo efetuado com estudantes de Letras sobre as representações de "Maghrébin", nas quais se pediram associações aos sujeitos numa condição normal (normativa), em que o aplicador se apresentou como estudante de Letras, e numa condição de descontextualização normativa, na qual o aplicador se apresentou como estudante de Direito. Na faculdade onde estes alunos estudam, os estudantes de Letras são percebidos, de acordo com o estereótipo que se têm deles, como mais tolerantes, com normas mais rígidas contra o racismo que os alunos de Direito.

Como resultados, obteve-se diferenças acentuadas nas representações nas duas condições. Na condição "normal" (estudantes de Letras respondem para entrevistador também de Letras) apareceram como elementos centrais palavras como: "geográfico", "cultura", "racismo", "calorosos"; e como elementos periféricos: "delinqüência", "igual", "impedidos de se integrar", "vítimas de racismo". Na condição de descontextualização (estudantes de Letras respondem para estudantes de Direito) apareceram os elementos: "geográfico", "delinqüência", "racismo", "imigração", como centrais e "não querem se integrar", "comida", "baixo nível econômico" como elementos periféricos (Abric, 2003). Assim, as expressões "delinqüência" e "não querem se integrar" podem ser elementos da zona muda. Na situação de descontextualização, portanto, os estudantes produziram muito mais associações negativas que em situação normal.

Concluindo sobre as condições de existência da zona muda, Abric (2003) chama a atenção ao fato de que ela diz respeito a certo tipo de representação: aquelas que representam objetos impregnados por valores sociais reconhecidos 
e partilhados. São objetos "sensíveis" no sentido que seu campo representacional comporta cognições e crenças que, se expressas, colocam em xeque valores morais ou normas sociais valorizadas pelos grupos. No entanto, em certas situações, os elementos da zona muda se expressam; e a pesquisa deve investigar as condições de expressão desses elementos.

A hipótese da zona muda coloca uma questão importante para a teoria do núcleo central: se as representações mudam segundo contextos normativos diferentes, o que se mantém estável numa representação? Pode-se ainda pensar em um núcleo central de toda representação? Para Abric (2003), o fato de existirem elementos mascarados ou escondidos na zona muda e de serem estes elementos os do núcleo central não implica na suposição de que o núcleo central de uma representação não seja estável. Abric reafirma sua hipótese de que "O conteúdo do núcleo central não muda segundo variações do contexto. Ele é simplesmente modulável. Certos elementos serão mais facilmente expressos que outros. No entanto, existem. O problema é fazê-los emergir." (Abric, 2003, p. 80).

\section{A pesquisa da zona muda nas representações sociais - primeiros trabalhos}

\section{Flament e as representações de estudo}

Uma pesquisa realizada por Flament (1999) sobre a representação de estudo em estudantes de Psicologia revelou o quanto respostas dadas a um questionário podem se adequar às normas do grupo de referência para quem o questionário é respondido. $\mathrm{O}$ autor tece a idéia de que as respostas que normalmente colhemos refletem as opiniões "bem vistas" (ou "mal vistas") por certas instâncias de referência, não porque os sujeitos se declarem sobre esta influência, mas porque as opiniões standart (colhidas em situação "normal") correlacionam-se com as opiniões de referência. Para Flament (1999), a idéia de que existe um aspecto normativo nas representações sociais é bem trabalhada pela "Escola de Aix".

Abric (1976) sugere que o núcleo central tem elementos normativos e funcionais. Abric e Tafani (1995) mostraram que certos elementos podem ser funcionais e normativos. Moliner (1994, 1995) propõe um modelo "bi-dimensional" que evidencia "campos" sendo que na zona do núcleo central, há o "campo" das normas. Flament (1994) propõe a consideração da representação social como inteiramente composta de "prescrições", isto é, de normas; o que não impediria os elementos de serem, conforme a ocasião, funcionais ou descritivos.

Flament (1999) partindo da suposição de que os questionários que habitualmente utilizamos para descrever as representações sociais são largamente o reflexo de discursos normativos atribuídos às diversas instâncias de referência, solicita a alunos que dêem suas representações de estudo em três tipos de situação: standart, quando os alunos respondem por si mesmos, na condição de serem "bem vistos" por professores ou pessoas acima de 40 anos, e na condição de serem "mal vistos" por essas mesmas pessoas.

Flament já havia obtido, em estudo anterior (Flament, 1994) a representação de estudo como "um meio de fazer amigos" como uma representação que pode ser "bem vista" por estudantes, mas "mal vista" por outros grupos de referência. Assim, se perguntando sobre quando representações revelam normas, o autor decide por este método operacional para testar em que medida as opiniões standart refletem a influência normativa de uma instância de referência e a qual instância os discursos dos sujeitos mais se correlacionam.

Flament (1999) passou primeiramente a 278 estudantes de Psicologia um questionário, na forma standart, na qual foram apresentados 15 itens (inspirados em Moliner, 1995) na forma de frases sobre os estudos (por exemplo: "os estudos são difíceis"; "os estudos permitem adquirir cultura"; "os estudos dão prazer"; "os estudos são um meio de obter uma profissão"; "os estudos são um meio de fazer amigos"; etc).

Os sujeitos deveriam colocar um sinal + nos itens que lhes parecessem mais característicos de "estudos" e um sinal - diante dos cinco itens que lhes parecessem os menos característicos. Após responderem o questionário standart, os sujeitos receberam dois outros questionários, iguais aos primeiros, mas "normativos", isto é, na qual se pedia que respondessem como o faria um estudante bem visto (depois mal visto) por seus professores (para outro grupo, por pessoas de 40 a 50 anos).

Depois do primeiro questionário, foi realizada a técnica de "Mise em Cause" (MEC) ou "Colocar em Xeque" com 100 sujeitos, tal como utilizada por Moliner (1995) onde foram apresentadas frases para as quais se deveria dizer se se tratavam de estudos ou não. Por exemplo: "Pode-se dizer que alguém faz seus estudos se o que ele faz não demanda trabalho?". As respostas deveriam ser sim ou não. Foram consideradas como elementos do núcleo central aquelas frases que tiveram ao menos $75 \%$ de refutação.

$\mathrm{Na}$ pesquisa de 1999, Flament encontra diferenças significativas nas respostas dos alunos às três condições do questionário: condição standart, condição de serem "bem vistos" por pais e professores, e condição de serem "mal vistos". Em todos os grupos, elementos intelectuais e práticos de estudo foram os mais escolhidos, no entanto, certos elementos ficaram mais evidentes num tipo de questionário que em outro; por exemplo, "amizade" foi o último item na condição standart e o quinto na condição "bem visto". Ou seja, foram obtidos diferentes "perfis" de representação conforme a condição do questionário. Houve diferenças, também, nos elementos das representações de alunos filhos de pais com nível superior de ensino ("herdeiros") ou com pais sem nível superior de ensino ("não-herdeiros"), sendo que os primeiros valorizaram mais aspectos "intelectuais" do estudo e os segundos, mais aspectos "práticos". O autor conclui que "O que pensamos ter estabelecido é que as respostas que colhemos habitualmente nos estudos de representação social são largamente (se não totalmente) o reflexo complexo de diversos modelos normativos pertinentes para o objeto da representação" (Flament, 1999, p. 50).

Foi, portanto, colocada por Flament (1999) a idéia de adequação normativa das representações sociais explicitadas em instrumentos como questionário e a importância de se levar em conta a influência de grupos de diferentes referências normativas de quem e para quem o sujeito fala quando responde aos questionários. Surgem as técnicas de substituição e descontextualização normativa. 


\section{Guimelli e Deschamps e as representações sobre ciganos}

A técnica de substituição, na qual os sujeitos podem responder como outros o fariam, segundo Abric (2003), já era utilizada em trabalhos fora do campo das representações sociais. Mas foi usada pela primeira vez na pesquisa em representações sociais por Guimelli e Deschamps (2000).

Segundo Guimelli e Deschamps (2000) a técnica das associações livres tem o objetivo de permitir o acesso a conteúdos das representações e, a partir da análise dos mesmos fazer ressaltar a parte comum dos diferentes discursos individuais. Mas, como dizem os autores, as associações nunca são "livres": é o pesquisador que as induz escolhendo as palavras indutoras; além disso, o enquadre em que são feitas as associações também as orienta em diferentes direções. Esse enquadre em que as associações são solicitadas (para uma pesquisa, o anonimato, a não preocupação com o individual e sim com o coletivo) impõe aos sujeitos uma seleção de associações. Como sugerem os autores, as primeiras palavras que vêm à mente nem sempre são as primeiras a serem expressas. Podem ser expressas as que parecem mais adequadas e mais socialmente aceitáveis ou admitidas num certo contexto. Assim, os autores colocam o objetivo de modificar o contexto psicossocial e verificar seus efeitos em associações verbais.

Guimelli e Deschamps (2000) solicitaram as representações sobre ciganos em dois contextos de produção de respostas: "normal" - sujeitos deveriam responder por si mesmos - e de "substituição" - respondiam pelos "franceses em geral". Primeiro, foram pedidas cinco associações a partir da palavra "cigano". Para um grupo de sujeitos (estudantes de Psicologia), as associações eram feitas primeiro na situação "normal" e depois na situação de "substituição"; para outro grupo, o inverso. Em seguida, os sujeitos deveriam avaliar as associações que fizeram, como positivas ou negativas dandolhes notas $(--,-, 0,+,++)$. Depois, deveriam dar o número de ciganos (em porcentagem de zero a 100) que teriam as características dadas nas associações. Os autores produziram, assim, três medidas de representação: o rank de aparecimento das associações (ordem de aparecimento das associações verbais); sua conotação positiva ou negativa; disparidade ou homogeneidade percebida para cada uma das respostas na escolha das porcentagens (zero a 100).

Como resultados principais, Gimelli e Deschamps (2000) obtiveram que o número de associação feitas na situação "normal" e de "substituição" foi semelhante; mas, apesar de muitos termos estarem presentes nas duas condições, as palavras com conotação mais negativa, como "ladrão", "sujo", "mendigo", "estrangeiro", "não-trabalhador" apareceram bem mais na situação de "substituição". Aconteceram diferenças, também, na ordem de aparecimento das palavras; a palavra "ladrão", por exemplo, no contexto de substituição é a primeira a aparecer e muito freqüente.

Assim, concluem os autores, houve termos que apareceram igualmente nas duas condições (pregnância), por exemplo, o elemento "nômade", e outros que apareceram diferentemente em cada condição. Os termos mais pregnantes provavelmente são os do núcleo central e se caracterizam por sua estabilidade. Outras representações apareceram conforme o contexto do questionário o que evidencia que podem ter sido consideradas, pelos sujeitos, como indesejáveis frente a um certo contexto. Duas hipóteses podem explicar esses resultados, segundo os autores. Pode ser que os sujeitos, simplesmente, tenham uma visão (ou adotem uma posição) mais positiva do que pensam da visão de outros ("os franceses em geral"). Mas parece razoável, aos autores, pensar que um efeito de desejabilidade social levou os sujeitos a mascararem avaliações negativas contra normativas.

Os resultados obtidos por Guimelli e Deschamps (2000) vão, segundo esses autores, na mesma direção das reflexões de Moscovici (1998) a respeito das representações racistas ou étnicas que provavelmente não desaparecem, mas ficam marginalizadas em certos períodos o que torna a sua expressão pouco provável, e em outros períodos podem ressurgir.

\section{Deschamps e Guimelli e as representações sociais de segurança e insegurança}

Considerando novamente que nem sempre o que os sujeitos dizem em associações verbais é uma produção "livre", mas "adequada" a diferentes sistemas de referência normativa, Deschamps e Guimelli (2004) realizaram uma pesquisa com o objetivo de estudar a organização interna das representações sociais de segurança e insegurança de bens e pessoas através de associações verbais. Pediram aos sujeitos que dessem 10 respostas associativas: cinco a partir do indutor "segurança" e cinco a partir do indutor "insegurança". Além de outras variáveis independentes (exposição a frases sobre "segurança" e "insegurança" de acordo com a técnica de "amorçage" ; contexto situacional dos sujeitos - Aix-enProvence e Lausanne e ordem de associações das palavras "segurança"e "insegurança") e foi novamente manipulado o contexto psicossocial do questionário sendo apresentado em duas condições, "normal" (responder por si mesmo) ou em condição de "substituição" (responder por um outro, "os franceses em geral", por exemplo). Assim, Deschamps e Guimelli (2004) pediram aos sujeitos que dessem as associações sobre "segurança" ou "insegurança" primeiro de acordo com "o que lhes vêm à cabeça" - situação "normal" e, depois como "os franceses em geral" - situação de substituição.

Como resultados principais, os autores confirmaram a hipótese de que as representações de "segurança" e de "insegurança" podem ser independentes, uma da outra; ou seja, são utilizados termos distintos em uma e outra, assim como podem ser usados antônimos entre uma e outra. Houve diferenças nas representações dos sujeitos de Aix e de Lausanne. "Insegurança" foi mais associada a "desemprego" e "pobreza" em Lausanne e em Aix, mais associada a "agressão" e "periferia". Com relação aos contextos de "substituição" e "normal" houve diferenças marcantes. No contexto "normal", por exemplo, as palavras mais associadas à "Segurança" foram: "calma", "ordem", "paz", "sonho", sinônimo de "compreensão", "autoridade" e "lei" nas quais se sobressaiu, de acordo com os autores, uma atividade cognitiva de descrição. No contexto de "substituição", apareceram respostas sobretudo ligadas às formas de se manter

6 Estamos mantendo o termo em francês: amorçage 
a segurança, fossem elas legais ("alarme", "vigia", "prisão"), fossem elas contestáveis socialmente ("menos estrangeiros") ou francamente ilegais ("armas").

Deschamps e Guimelli (2004) ressaltaram como essas respostas pertencem a um domínio pouco aprovado que podem "manchar" a imagem de quem as faz, pois, mesmo quando são respostas dentro da lei, elas tendem a afirmar a violência contra a violência; o que vai contra os valores sociais mais aprovados. No contexto de "substituição", como se diminuiu o grau de implicação dos sujeitos, essa respostas puderam aparecer e o fizeram de modo dominante. $\mathrm{O}$ mesmo fato aconteceu com a palavra indutora "Insegurança". Na situação "normal" foi associada a "medo", "perigo", "acidente", "incerteza", "fraqueza", "doença"; ou seja, referiram-se a sentimentos e emoções ligadas à insegurança, e mais descritivos. Na situação de "substituição" as associações mais freqüentes referiram-se a "periferia", "jovem", "droga", "estrangeiros", "desemprego", ligadas, portanto, às causas da insegurança e mais atributivas que descritivas. Essas associações seriam mal aceitas socialmente ou contrárias aos valores morais ou normas sociais valorizadas pelo grupo de referência.

Embora Deschamps e Guimelli (2004) levantem a possibilidade de que as representações na situação de "substituição" apenas revelem o que os sujeitos pensam ser as representações de outros, conhecendo, portanto, os estereótipos de um grupo (como no caso, "os franceses em geral"), é mais provável que as respostas evidenciem o efeito da "zona muda". Os autores ressaltam, finalmente, a influência das condições em que as representações sociais são colhidas nas modificações dos dados obtidos, principalmente quando os objetos de representação são objetos sensíveis às normas sociais. Mais uma vez, portanto, estava demonstrado um efeito de desejabilidade ou adequação social nos questionários de representação social.

\section{A continuidade de estudos sobre a zona muda na escola de Aix-en-Provence}

Seguindo a linha de investigação aberta em Aix-enProvence sobre a "zona muda das Representações Sociais", começam a surgir outros trabalhos investigando este fenômeno. São exemplos as monografias de Master $1^{7}$ de Rachida, El Bourkadi, e Abouabadallah (2002/2003) sobre as representações de "maghrébins" e de Chavanel e Romain (2004) sobre as representações sociais de muçulmanos na França.

Rachida e cols. (2002/2003), estudaram as representações que alunos "não-maghrébinos" fazem dos maghrébinos. Segundo os autores, quando os franceses falam de imigrantes, evocam, sobretudo, os negros africanos, os turcos e os maghrébinos. Esses grupos podem ser alvo de racismo aparente ou "disfarçado", como explicam Pettigrew e Meertens

7 Na Faculdade francesa, após o terceiro ano de curso, há dois anos de Master nos quais os alunos escolhem certas especializações em Psicologia e, dependendo das escolhas, devem fazer pesquisas como monografias de fim de curso. Os trabalhos que agora apresentamos são referentes a monografias do Master 1 em Psicologia Social, orientados por professores do Laboratório de Psicologia Social de Aix-en-Provence.

8 Subtle, em inglês ou voilé, em francês.
(1995). Segundo esses autores, existe um tipo de preconceito mais velado que evita afirmar características negativas ao grupo alvo, mas que dá menos respostas positivas. Esse racismo "disfarçado" seria "frio", "distante", "indireto" e é expresso de tal forma a não ser condenado pelas normas sociais vigentes. Revela-se, principalmente por três formas: a defesa de valores tradicionais, a exageração de diferenças culturais, notadamente em nível de crenças religiosas, e a negação de emoções positivas ao exogrupo.

Para investigar as representações sobre maghrébinos, os autores usaram a técnica da substituição e da descontextualização normativa. A primeira consistiu em pedir aos sujeitos, alunos da faculdade de Aix-en-Provence, que respondessem a um questionário com frases neutras, contra ou a favor dos maghrébinos na condição normal (o que pensam sobre) e nas condições de substituição (como se fossem racistas ou como se fossem amigos de maghrébinos).

Na técnica de descontextualização normativa, os autores utilizaram-se de duas aplicadoras de questionário, uma com características de maghrébina e outra com características de francesa. Foram montados grupos diferentes de sujeitos em função das combinações das variáveis manipuladas.

Para a confecção do questionário, realizaram, primeiramente, entrevistas semi-dirigidas sobre os maghrébinos e levantaram os temas mais comumente usados, como: racismo, integração, religião, insegurança, terrorismo; e aspectos positivos, como: hospedeiros, calorosos. A partir desses temas, construíram um questionário com 21 frases às quais os sujeitos marcavam sua concordância ou não numa escala de quatro pontos.

Como resultados principais, Rachida e cols. (2002/2003) obtiveram respostas muito diferentes nas duas variáveis manipuladas na pesquisa: a condição do questionário (de substituição versus normal) e a descontextualização normativa (entrevistadora maghrébina e francesa). As respostas na condição de "racista" foram muito diferentes das feitas em condição "normal" ou de "amigos de maghrébinos"; estas últimas mais semelhantes entre si. Além disso, as respostas à pesquisadora maghrébina foram diferentes das respostas à pesquisadora francesa. Em relação à técnica de descontextualização normativa, foi na condição de aplicadora não-magrhébina que os sujeitos mostraram respostas mais negativas. Em relação à técnica de substituição, foi na condição de "racista" que os sujeitos expressaram mais seu acordo a frases negativas contra os maghrébinos.

Os resultados revelaram, portanto, uma plasticidade grande nas representações sociais sobre os maghrebinos em função das situações do questionário variarem o lugar do qual se fala (substituição) e o para quem se fala (descontextualização normativa). Os autores colocam a hipótese da atuação da "zona muda nas representações", embora levantem a dúvida de se as variações de respostas, na condição de substituição, apenas revelem uma "transparência das representações", isto é, um conhecimento pelos sujeitos dos estereótipos de outros grupos pelos quais falam, no caso, os racistas.

Um trabalho semelhante foi realizado por Chavanel e Romain (2004). Neste, foram investigadas as representações sociais sobre muçulmanos. Também neste estudo foram utilizadas frases neutras, positivas e negativas sobre muçulmanos e pediu-se aos sujeitos, 200 estudantes da 
Faculdade de Letras em Aix-en-Provence, que marcassem seu acordo ou desacordo às frases a partir de uma escala de 11 pontos. Duas condições foram manipuladas na aplicação dos instrumentos de pesquisa: a presença de um texto neutro sobre os muçulmanos apresentado antes do questionário de frases a um dos grupos de sujeito e a participação de duas entrevistadoras, uma com nome e de origem muçulmana e outra com nome e origem francesa, como técnica de descontextualização normativa. A presença do texto neutro, como ativação de estereótipos, foi inspirada em estudos americanos que usaram este procedimento, tal como os de Devine (1989) e Gilbert e Hixon (1991) baseados na hipótese de que certas atividades podem ativar os estereótipos e impedir o aparecimento deles, como forma de alertas, em investigações posteriores. Chavanel e Romain (2004) usaram o texto de ativação de estereótipo para investigar se o mesmo inibiria as representações situadas na zona muda. O texto continha informações e descrições imparciais sobre a imigração de muçulmanos na França.

Como resultados principais, as autoras obtiveram diferenças nas representações, principalmente em função da variável relacionada às aplicadoras. Foi em presença da aplicadora árabe que foram obtidas menos respostas negativas aos muçulmanos. Foi pequeno o efeito da presença do texto neutro, mas ele se manifestou no sentido de diminuir o apoio a frases negativas sobre os muçulmanos. Houve, também, um efeito relacionado ao sexo dos sujeitos. Os homens apresentaram menos respostas de apoio às frases negativas sobre os muçulmanos que as mulheres, o que sugeriu uma adequação de respostas ao sexo oposto. Mais uma vez, os resultados obtidos neste estudo, confirmam um efeito de adequação das respostas dos sujeitos à situação do questionário e as respostas preconceituosas novamente ficaram mais evidentes na condição de descontextualização normativa.

Finalmente, encontramos a pesquisa de Gaymard (2003) que investiga aspectos normativos das representações sociais num contexto de biculturalismo, testando, num grupo de estudantes maghrébinas, parte delas em condições de ruptura familiar, a influência do modelo parental sobre suas respostas a oito temas: igualdade dos homens e mulheres em casa; independência dos jovens; igualdade de acesso aos estudos para as mulheres e os homens; casamento e as mulheres; virgindade; fumo; religião e acesso a outras culturas.

Os temas foram inspirados em Malewska-Peyre e cols. (1982). Os temas foram apresentados em pares de frases como proposições estereotipadas do tipo normativo. Para cada par de frases, pediu-se aos sujeitos que escolhessem qual a proposição que correspondia a sua opinião (condição de si mesmo), a de seu pai e a de sua mãe. O questionário foi apresentado em quatro condições: condição standart, na qual os sujeitos deveriam escolher as frases segundo a sua própria opinião, e três condições de substituição; na primeira, pedia-se que marcassem as frases como o faria uma estudante maghrébina bem vista por seus pais; na segunda condição de substituição, deveria responder como uma estudante mal vista por seus pais e na terceira condição, como uma estudante cujos pais não fossem de origem maghrébina.

Como resultados principais, Gaymard (2003) obteve marcáveis efeitos da influência do modelo normativo "bem visto pelos pais" nas respostas das estudantes. A condição de substituição por um modelo ocidental (sem pais maghrébinos) obteve resultados mais diferenciados entre as jovens em ruptura familiar. Na condição standart e nas demais, ficou evidente que certas frases tiveram diferentes graus de importância; algumas foram percebidas como mais tradicionais que outras tanto para as estudantes, quando respondiam por si, como quando respondiam pelos seus pais.

Os temas relativos a fumo, religião, virgindade, casamento, e independência foram os que mais se opuseram nas condições "bem visto" e "mal visto", outros itens como instrução e acesso a outras culturas, foram menos diferenciados em função das condições do questionário. A autora comenta que tudo se passa como se os sujeitos distinguissem os aspectos normativos absolutos e condicionais entre seus pais. Assim, Gaymard conclui que: "os resultados mostram que os indivíduos não são prisioneiros de suas representações sociais" (2003, p. 88). As respostas das jovens em condição standart foram influenciadas por modelos normativos e as mesmas foram capazes, em condição de "substituição", de distinguir os aspectos absolutos e condicionais entre seus pais.

Demonstrou-se novamente, com o estudo de Gaymard (2003), um efeito normativo do questionário nas condições standart e de "substituição", assim como a existência de aspectos mais ou menos "negociáveis", condicionais, das representações que podem mudar nas diferentes condições do questionário. O estudo sugere, também, o conhecimento que um grupo de sujeitos (as jovens magrhébinas) tem das representações de seus pais ou de jovens não magrhébinos em temas normativos. O que pode explicar a adaptação das respostas a cada grupo focado nas condições de substituição.

\section{A zona muda e os fenômenos de transparência das representações e de influência social}

Os estudos que aqui descrevemos deparam-se com o fenômeno da mudança das representações de um objeto quando um grupo fala por si e por outros. De certa forma, este fenômeno pode revelar o efeito de adaptação dos discursos às normas sociais vigentes de forma que quando os sujeitos falam por si, tenderiam a não demonstrar representações "mal vistas", condenáveis pelos grupos de referência; é a hipótese da zona muda, tal como explicitada por Guimelli e Deschamps (2000), Abric (2003), Deschamps e Guimelli (2004). Pode-se colocar, também, outra hipótese para essa adequação das respostas às condições dos questionários, relativa ao fenômeno da "transparência das representações". A transparência consiste no conhecimento que um grupo tem das representações de um mesmo objeto por outro grupo. Neste caso, as respostas de um grupo ao falar por outro não revelariam necessariamente aspectos "escondidos" ou "condenáveis" das representações que não poderiam ser ditas livremente pelos próprios sujeitos, como um fenômeno de "projeção", mas apenas o conhecimento que um grupo tem das representações ou estereótipos de outros.

Flament e Rouquette (2003) discutem o fenômeno da transparência quando sugerem a investigação das relações (de semelhança, de oposição, ou de coordenação) entre as representações de um mesmo objeto social de dois grupos suscetíveis de se comunicarem ou de interagirem a respeito 
do objeto representado. Os autores relatam o estudo de Campbell, Muncer, Guy e Banim (1996) que investigou as representações de agressão em homens e mulheres. Nessa pesquisa, além de levantarem as representações de cada grupo, os autores pediram aos homens que explicitassem as representações das mulheres e a estas que explicitassem as representações dos homens, em condição de substituição, portanto. Os autores obtiveram que homens e mulheres têm representações diferentes de agressão; mais expressiva e por falta de controle, por exemplo, entre as mulheres, e mais instrumental para os homens. No entanto, ambos os grupos foram capazes de representar, consistentemente, o que o outro grupo pensa revelando, então, um conhecimento das representações do outro grupo.

Flament e Rouquette (2003) descrevem, também, o estudo de Gonthier e Jeanson (2000) que investigaram as representações de toxicomania em jovens e em pessoas de 40 a 50 anos. Os sujeitos deveriam avaliar frases através de uma escala de acordo ou desacordo, respondendo por si mesmos (condição standart) e, depois como o outro grupo o faria (os jovens respondendo pelos mais velhos e estes pelos jovens). Os autores interessaram-se em saber até que ponto uma representação suposta por grupo sobre outro, ou melhor, imputada a um grupo por outro, reflete a representação "verdadeira". Os resultados analisados através de regressão múltipla mostraram uma boa estimativa de cada grupo sobre a realidade da representação do outro. Ou seja, constatou-se uma transparência importante entre os jovens e as pessoas de mais de 40 anos. Tudo se passou, como comentam Flament e Rouquette (2003), como se os estudantes e as pessoas de outras gerações discutissem suficientemente toxicomania para conhecerem o que cada grupo pensa.

Assim, por esses relatos, sugere-se o fenômeno de transparência para explicar os estereótipos que aparecem quando um grupo fala das representações de outro. Desta forma, quando estudantes falam pelos "franceses em geral" ou pela "opinião pública" ou ainda, pelos "racistas", não obrigatoriamente estariam projetando suas próprias representações condenáveis, mas falando do que conhecem das representações de outros grupos com os quais convivem.

Continua, no entanto, a questão da adequação dos questionários as suas condições de aplicação. Se os jovens falam diferentemente quando falam pelo "público em geral" do que quando falam por si mesmos, eles são também o "público em geral"; as representações que aparecem nessa condição também são suas. Abric (2003) na técnica de substituição recomenda que o grupo que substitui o sujeito não seja muito distante do próprio sujeito, de forma que este se encontrará menos implicado, mas não totalmente afastado das representações daquele grupo. Além disso, na técnica de descontextualização normativa, com a mudança do aplicador do questionário, os sujeitos continuam falando por si, de suas representações, só que, possivelmente, frente a um outro grupo de referência, e neste caso, também é forte o efeito de adequação de respostas, ou seja, a zona muda se evidencia.

Continua forte, portanto, a hipótese da adequação dos questionários à influência de normas sociais vigentes dentro de um grupo de referência para os sujeitos que respondem a um questionário. $\mathrm{O}$ que nos leva às possíveis relações entre a teoria de influência social e a as representações sociais.
Mugny, Quinzade e Tafani (2001) discutem interrelações possíveis entre os processos de influência social e os de mudança nas representações sociais. Os processos de influência social estão, segundo os autores, no centro das atividades humanas e se exprimem pelo fato de que freqüentemente mudamos de opinião ou crenças quando tomamos conhecimento de opiniões ou crenças partilhadas por outras pessoas.

Em síntese, existem duas correntes sobre influência social, a funcionalista e a interacionista. Na primeira, a influência é explicada a partir do poder que uma fonte de influência ${ }^{9}$ exerce sobre a população alvo e a considera uma relação assimétrica unidimensional na qual o alvo está em posição de dependência em relação à fonte de influência; esta é uma autoridade institucional, uma maioria, um líder. O grupo é considerado como um sistema social que funciona de forma otimizada e que mantém um equilíbrio interno quase homeostático. Seu funcionamento é perturbado quando um ou mais indivíduos recusam-se a se conformar às normas do grupo sendo que uma diminuição da coesão do grupo ameaça a existência do mesmo. As pressões exercidas têm como função induzir os membros desviantes a se conformarem. Nessa perspectiva, as normas, crenças, opiniões ou outras cognições são "petrificadas" num estado único consensual, universal, imutável.

Numa segunda perspectiva, a interacionista, considerase as normas, crenças e opiniões como plurais, relativas, e, por natureza, mutáveis. Nesse caso, outras entidades podem exercer influência no grupo; como as minorias intragrupo ou exteriores ao grupo (Moscovici, 1996), e isso pode se dever à consistência da minoria na defesa de seu ponto de vista $\mathrm{e}$ no seu estilo de negociação; ou seja, na sua capacidade de introduzir um conflito social.

Considerando-se a segunda perspectiva que explica os processos de influência social, podem se distinguir dois níveis de influência:

- a influência manifesta, visível pela fonte de influência e pelo alvo, na qual ocorrem mudanças públicas de opinião ou de atitude e imediatas em resposta à pressão à conformidade introduzida, mesmo implicitamente pela fonte; - a influência latente, mais profunda, dependente de uma elaboração cognitiva do alvo de influência sobre os pontos de vista opostos. Traduz-se por mudanças indiretas, privadas ou diferenciadas que aparecem apesar do fato da fonte não exercer mais a pressão à autoridade.

Nesses processos, há "conformidade" (complaisance) quando o indivíduo mostra apenas uma mudança superficial de opinião e unicamente manifesta; e há "conversão" (conversion) quando a influência é latente. Podem existir diferentes casos em que esses fenômenos acontecem dependendo de variáveis como o tipo de autoridade da fonte de influência (de poder ou epistemológica); o valor atribuído ao seu discurso pelo alvo; o tipo de relação social estabelecida entre a fonte e o alvo, na qual podem estar presentes ameaças à identidade do alvo ou relação de cooperação ou aprendizagem com a fonte; sentimentos de capacidade ou incapacidade da população alvo em relação à fonte de influência e atribuídos a esta pelo alvo, e outras.

9 Os autores usam sempre termos "source" para se referir a uma fonte de influência e "cible" para se referir à população alvo da influência. 
Mugny e cols. (2001) explicam que do ponto de vista das teorias de influência social, as representações sociais que os indivíduos possuem podem ser consideradas como sendo construídas e apropriadas numa cultura dada através de interações sociais e, notadamente, em processos de influência que se fundam em relações de interdependência e de trocas de informações (crenças, opiniões, atitudes e guias de comportamento) entre diversas entidades sociais. Assim, mudanças de representações podem indicar diferentes relações entre fontes de influência e alvo em situações de conflitos.

Considerando os processos de influência social, pode-se pensar que a adequação que os sujeitos têm mostrado em situações de descontextualização normativa, quando se muda a pessoa para quem se responde o questionário, pode ser similar à exposição dos sujeitos às opiniões de uma fonte de influência. $\mathrm{O}$ aplicador do questionário, ou a autoridade que ele representa (para quem se faz a pesquisa, a instituição que a baliza, a autoridade do pesquisador) transparece na situação de pesquisa e os sujeitos interrogados sofreriam a influência das opiniões que pensam ser as dele. Há, portanto, adequação das respostas em função de para quem se responde, com mudanças nas representações.

Mugny, Moliner e Flament (1997) testaram a hipótese de mudança nas representações sociais em processo de influência social investigando as representações sobre grupo ideal de amigos. Sabe-se, por diversos estudos anteriores, que nessa representação a ausência de hierarquia no grupo é um elemento central e a convergência de opiniões, um elemento periférico. Manipulando diversas variáveis, os autores expuseram estudantes que tinham as representações de grupo de amigos ideal tal como as já investigadas, à leitura de um texto atribuído a uma autoridade científica na qual se defendia o ponto de vista que um grupo de amigos ideal pode ter um líder, portanto, um ponto de vista oposto ao dos estudantes. Como resultados principais, os autores constataram uma forte influência do texto "científico" nas representações dos estudantes, de forma que os mesmos passaram a admitir a existência de um grupo ideal que continha liderança. Houve mudança, portanto, no núcleo central da representação. Esta mudança pode ser explicada como uma transformação progressiva uma vez que os sujeitos continuaram afirmando que preferiam um grupo ideal sem liderança. No entanto, a condição da fonte de influência - uma "autoridade científica" em situação escolar, numa relação epistêmica e sem que houvesse ameaça à identidade dos estudantes, parece ter produzido uma mudança de representação mais do que apenas manifesta.

Outros estudos dentro da teoria de influência social investigaram o papel de normas antidiscriminação intragrupo como fonte de influência de representações étnicas em processos de discriminação entre grupos. Falomir-Pichastor, Muñoz-Rojas, Invernizzi e Mugny (2004) realizaram três estudos investigando o papel da ameaça sentida por um grupo em relação a outro e a influência de normas antidiscriminação intragrupo. Perguntaram-se até que ponto normas antidiscriminação que existem atualmente nas sociedades ocidentais podem produzir mudanças de representações entre grupos que se sentem ameaçados pela presença de imigrantes. Discutiram como normas antidiscriminação são cada vez mais aceitas e desejáveis socialmente e que uma das conseqüências disso é o aparecimento de um racismo dissimulado (Pettigrew \& Meertens, 1995; Deschamps \& Lemaine, 2004). Assim, estar de acordo com normas do grupo, ou sentir-se em desacordo com as mesmas, pode ser uma variável importante para explicar a exibição ou não de respostas racistas. Por outro lado, a influência das normas antidiscriminação parece diminuir em situações em que os grupos se sentem ameaçados por outro. As ameaças podem ser de natureza econômica (competição por trabalho, desemprego, aquisição de bens, segurança) ou simbólica (conflito de valores, religião, ameaças identitárias).

\section{Considerações Finais}

Os estudos que evidenciam uma zona muda das representações sociais defrontam-se com um antigo problema das investigações em Psicologia: até que ponto o que as pessoas respondem nos questionários correspondem ao que realmente pensam? As experiências realizadas sobre a zona muda, dentro da teoria de representação social, mostram a presença de transformações nas representações obtidas por questionários (escalas de avaliação de itens, testes de centralidade dos elementos da representação) em situações que se variam duas condições: para quem os sujeitos falam nos questionário - descontextualização normativa - e a partir de quem fala, se por si ou por outros - situação de substituição.

Estas transformações ou adaptações das representações quando o sujeito fala por outro, ou fala para outros, podem ser explicadas como projeções de representações verdadeiras na voz de outro, como sugerem os estudos de Abric (2003), Guimelli e Deschamps (2000), Deschamps e Guimelli (2004) e outros. Podem, no entanto, também, representar "transparências de representações", nas quais os sujeitos apenas revelam o conhecimento que têm das representações de outros grupos, tal como explicam Flament e Rouquette (2004). Podem ainda sugerir o fenômeno de influência social, tal como sugerido por Mugny e cols. (2001), no qual mudanças de representação podem ocorrer em função de diferentes relações que estabelecem com uma fonte de influência, seja esta uma autoridade, uma maioria, uma norma intragrupo, uma minoria.

Em todas essas possibilidades, a presença das normas sociais é atuante. Seja por projeção, por transparência, por adequação a uma fonte de influência, em todas as situações de representações de um grupo por outro se pode inferir a presença de normas que parecem orientar quais representações seriam as mais adequadas, desejáveis em cada situação e que podem produzir modificações, mesmo centrais, nas representações. Assim, o fenômeno da zona muda abre um campo de investigação sobre representação social e normas sociais que precisa continuar a ser explorado.

Os estudos sobre zona muda também colocam um desafio metodológico à teoria das representações sociais que se refere ao modo como as representações sociais são coletadas. Como afirmam Deschamps e Guimelli (2004), o modo de coleta pode interferir na forma como as representações aparecem. Assim, é preciso pensar na necessidade de uma maior diversidade e plasticidade nas técnicas de investigação das representações sociais com a reinclusão, pensamos nós, de técnicas mais qualitativas de investigação, como entrevistas 
e observações de práticas, tal como aquelas propostas por Jodelet (2003).

\section{Referências}

Abric, J. (1976). Jeux, Conflits et représentations sociales, Thèse de doctorat, Université de Pronvence, Aix-en-Provence.

Abric, J. C. \& Tafani, E. (1995). Nature et fonctionnement du système central d'une représentation sociale: la représentation de l'entreprise. Cahiers Internationaux de Psychologie Sociale, 28(4), 22-31.

Abric, J. C. (1996). De l'importance des représentations sociales dans les problémes des l'exclusion sociale. Em J. C. Abric (Org.), Exclusion Sociale, insertion et prévention (pp. 11-17). Saint-Agne: ÉRÈS.

Abric, J. C. (2003). La recherche du noyau central et de la zone muette des représentations sociales. Em J. C. Abric (Org.), Méthodes d'étude des représentations sociales (pp. 59-80) Saint-Agne: ÉRÈS.

Campbell, A.; Muncer, S.; Guy, A. \& Banim, M. (1996). Social representation of aggression: crossing the sex barrier. European Journal of Social Psychology, 26, 135-147.

Chavanel, S. \& Romain, D. (2004). La zone muette de la représentation sociale des musulmans: une nouvelle approche méthodologique. Mémoire de maîtrise, Université AixMarseille, Université de Provence. UFR en Psychologie, Sciences de l'Éducation.

Deschamps, J. C. \& Lemaine, G. (2004). "Je ne suis pas raciste, mais...”: racisme masqué dans les pays de 1 'Union Européenne. Psychologie \& Société, 7, 139-169.

Deschamps, J. C. \& Guimelli, C. (2004). L'organisation interne des représentations sociales de la sécurité/insécurité et hypothèse de la «zone muette» (2004). Em J. L. Beauvois \& R. V. Joule, J. M. Montreil. Perspectives Cognitives et Conduites Sociales. 300-323. Tomo IX . Rennes: Press Universitaire de Rennes.

Devine, P. (1989). Stereotypes and Prejudice: their automatic and controlled components. Journal of Personality and Social Psychology, 56(1), 5-18.

Falomir-Pichastor, J. M.; Muñoz-Rojas, D.; Invernizzi, F. \& Mugny, G. (2004). Perseived in-groupe threat as factor moderating the influence of in-groupe norms ou discrimination against foreigners. European Journal of Social Psychology, 34, 135153.

Flament, C. (1994). Représentation Social, consensus et corrélation. Papers on Social Representations, 3(2), 184-193.

Flament, C. (1999). La représentation sociale comme système normatif. Psychologie et Société, 1, 29-53.

Flament, C. \& Rouquette, M. L. (2003). Anatomie des idées ordinaires. Comment étudier les représentations sociales. Paris: Armand Colin, VUEF.

Gaymard, S. (2003). Les techiniques de substituition dans l'étude des représentations sociales: un révélateur des aspects normatifs. Em Actes de Colloque: Normes sociales et processus cognitifs. Pointers, p. 85-88.
Gilbert, D. T. \& Hixon, J. G. (1991). The Trouble of Thinking: Activation and Application of Stereotypic Beliefs, Journal of Personality and Social Psychology, 60(4), 509-517.

Gonthier, B. \& Jeanson, M. (2000). Étude sur la représentation social de la toxicomanie: entre deux générations. Maîtrese Psychologie Sociale, Université de Provence, Aix-en-Provence.

Guimelli, C., Deschamps, J. C. (2000). Effet des contextes sur la production d'associations verbales. Le cas des représentations sociales des Gitanes. Les Cahiers Internationaux de Psychologie Sociale, 47, 44-54.

Jodelet, D. (1996). Représentations sociales de la maladie mentale et insertion des malades mentaux. Em J. C. Abric (Org.), Exclusion Sociale, insertion et prévention (pp. 97-111). SaintAgne: ÉRÈS.

Jodelet, D. (2003). Aperçu sur les méthodes qualitatives. Em S. Moscovici \& F. Buschini (Orgs.), Les méthodes des sciences humaines (pp.139-162). Paris: Presses Universitaires de France.

Maleska-Peire, H.; Taboada-Leonetti, I.; Zaleska M.; Basdevant C.; Bonerandi, J. O.; Eyzat, A.; Lahalle A. \& Nery M. (Orgs.) (1982). Crise d'identité et deviance chez les jeunnes immigrés. Centre de Formation et de Recherche de L'Education Surveillé, Vaucresson, Paris, La Documentation Française.

Moliner, P. (1994). Les deux dimensions de représentations sociales. Revue Internationale de Psychologie Sociale, 2, (7), 73-86.

Moliner, P. (1995). Noyau central, principes organizateurs et modèle bidimensional de représentatio social: vers une integration théorique. Cahiers Internationaux de Psychologie Sociale, $28,44-55$.

Moscovici, S. (1996). Psychologie des minorités actives. Paris: Puf.

Moscovici, S. (1998). Comment voit-on le monde? Représentations sociales et réalité. Sciences Humaines, Hors Série, 21, 11-13.

Mugny, G.; Moliner, P. \& Flament, C. (1997). De la pertinence du processus d'influence sociale dans la dynamique des représentations sociales: une étude exploratoire, Revue Internationale de Psychologie Sociale, 1, 31-49.

Mugny, G.; Quinzade, A. \& Tafani, E. (2001). Dynamique représentationnelle et influence sociale. Em P. Moliner. La dynamique des représentations sociales (pp.123-161). Grenoble: Press Universitaire de Grenoble.

Pettigrew, T. F. \& Meertens, R.W. (1995). Subtle and blatant prejudice in western. European Journal of Social Psychology, 25, 57-76.

Rachida, M.; El Bourkadi, M. \& Abouabadallah, N. (2002/2003). La zone muette de la représentation sociale du Maghrébin, Memoire de maîtrise, Université de Provence. UFR Psychologie Science de l'Éducation. 